Acesso à

\section{contracepção e ao diagnóstico do câncer de colo uterino em Belo Horizonte: uma contribuição metodológica aos estudos quanti-quali}

\author{
Paula Miranda-Ribeiro* \\ Andréa Branco Simão** \\ André Junqueira Caetano*** \\ Ignez Helena Oliva Perpétuo ${ }^{\star \star \star *}$ \\ Marisa Alves Lacerda ${ }^{\star \star \star \star *}$ \\ Maria Eponina de Abreu e Torres ${ }^{\star \star \star \star \star \star}$
}

\section{Introdução}

O projeto Aspectos Quantitativos e Qualitativos Acerca do Acesso à Contracepção e ao Diagnóstico e Tratamento de Câncer de Colo Uterino: uma proposta de análise para o Município de Belo Horizonte, MG ${ }^{1}$ teve como objetivo avaliar, entre as muitas ações desenvolvidas pelo Programa de Orientação e Assistência ao Planejamento Familiar e à Saúde Reprodutiva no município de Belo Horizonte, aquelas destinadas à contracepção e ao diagnóstico e tratamento do câncer de colo uterino, enfatizando a percepção das mulheres residentes no município sobre o acesso a esses serviços.

Em relação à contracepção, buscou-se verificar em que medida as mulheres entre
18 e 59 anos de idade, sexualmente ativas e usuárias de contracepção, procuravam a rede básica de saúde pública para obtenção do método utilizado, identificando os perfis das usuárias e não-usuárias de contracepção pela rede do SUS (Sistema Único de Saúde). Em seguida, investigou-se como as mulheres dos diferentes perfis encontrados percebiam a questão do acesso à contracepção, comparando as que recorriam ao SUS para obtenção de métodos contraceptivos com aquelas que não o faziam.

Quanto ao acesso a diagnóstico e tratamento do câncer de colo uterino, o primeiro objetivo era verificar se, e com que freqüência, as mulheres entre 18 e 59 anos que já haviam tido ao menos uma relação sexual realizavam o exame de Papanicolau, considerado uma das estratégias mais simples, baratas e eficazes de prevenção deste tipo de câncer. Um segundo objetivo era identificar perfis de usuárias e não-usuárias do SUS, segundo o acesso ao diagnóstico e tratamento de câncer de colo de útero. Finalmente, buscou-se entender a percepção das mulheres entrevistadas sobre a questão do acesso ao diagnóstico e ao tratamento do câncer de colo uterino.

Este texto não trata dos resultados propriamente ditos, mas sim de uma contribuição metodológica oferecida pelo projeto.

\section{Metodologia}

Para atingir os objetivos propostos, a pesquisa foi dividida em duas etapas: uma de natureza quantitativa e outra qualitativa. A etapa quantitativa utilizou os dados provenientes do Programa Saúde Reprodutiva, Sexualidade e Raça/Cor (SRSR), cujo levantamento de campo foi realizado pelo

\footnotetext{
* Professora associada do Departamento de Demografia e pesquisadora do Cedeplar/UFMG.

${ }^{* *}$ Professora da PUC Minas e pesquisadora do Cedeplar/UFMG.

${ }^{* * *}$ Professor da PUC Minas e pesquisador do Cedeplar/UFMG.

${ }_{* * * *}$ Professora associada do Departamento de Demografia e pesquisadora do Cedeplar/UFMG.

***** Doutoranda do Programa de Pós-Graduação em Demografia, Cedeplar/UFMG.

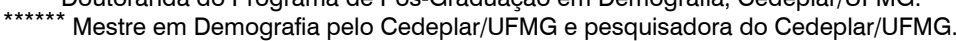

1 Projeto financiado pelo Prosare 2005 - Programa de Apoio a Projetos em Sexualidade e Saúde Reprodutiva, com apoio da John D. e Catherine T. MacArthur Foundation. Além da equipe Cedeplar que assina este artigo, o projeto contou com profissionais da organização não-governamental Mulher e Saúde - Musa.
} 
Cedeplar/UFMG, nos municípios de Belo Horizonte e Recife, em 2002. Em Belo Horizonte, foram entrevistadas $1.301 \mathrm{mu}$ Iheres entre 15 e 59 anos, as quais, com a expansão da amostra, representam 875.476 mulheres. ${ }^{2}$

O método Grade of Membership (GoM) ${ }^{3}$ foi utilizado para traçar os perfis das mulheres belo horizontinas usuárias e não usuárias do SUS, segundo o acesso à contracepção e ao diagnóstico e tratamento do câncer de colo uterino. O GoM foi escolhido porque, diferentemente da maioria dos métodos estatísticos, não se baseia na teoria clássica dos conjuntos (a qual preconiza que cada elemento pertence a um único conjunto), mas sim na teoria dos conjuntos nebulosos, segundo a qual um determinado elemento pode pertencer parcialmente a múltiplos conjuntos, possuindo um escore ou grau de pertinência aos conjuntos que varia no intervalo entre zero e um. Um escore de 0 indica que o elemento não possui nenhuma das características do perfil $X$, enquanto um escore de 1 mostra que a mulher possui todas as características do perfil $X$.

As variáveis incluídas nos modelos de GoM foram divididas em quatro dimensões: demográfica; de conhecimento; de acesso; e socioeconômica. Foram delineados quatro perfis de referência, com base em quatro níveis de escolaridade. O perfil 1 foi composto por mulheres entre 0 e 3 anos de estudo e com maior probabilidade de terem outras características relacionadas às variáveis de interesse. $O$ perfil 2 agregou as mulheres de 4 a 7 anos de estudo, o perfil 3 reuniu as de 8 a 11 anos de estudo, enquanto no perfil 4 ficaram as mulheres de 12 ou mais anos de estudo. Além dos quatro perfis de referência, foram gerados, ainda, outros três mistos. Devido à heterogeneidade dos dados analisados, havia a possibilidade de que boa parte das entrevistadas pertencesse a mais de um perfil de referência. Assim, a fim de garantir que todas as mulheres fossem enquadradas em algum perfil, os mistos foram gerados com base na combinação dos diferentes valores dos graus de pertinência das observações. ${ }^{4}$

A seleção dos entrevistados costuma ser um dos pontos frágeis dos estudos de natureza qualitativa, uma vez que o perfil daqueles a serem recrutados costuma ser decidido com base em aspectos teóricos e na literatura pertinente, sem que se saiba, com certeza, se as características apontadas pela literatura se aplicam à população em estudo. Em geral, diz-se que os critérios utilizados para o recrutamento dos entrevistados são subjetivos. Ao utilizar os perfis delineados pelo GoM para o recrutamento das entrevistadas, o problema da subjetividade na seleção das entrevistadas foi minimizado, uma vez que o recrutamento das mesmas obedeceu a critérios estabelecidos pela etapa quantitativa do projeto, que podem ser considerados, em grande medida, objetivos, pois foram gerados a partir de dados representativos da população em estudo. Ainda assim, a subjetividade não foi totalmente eliminada, uma vez que a seleção das entrevistadas não foi feita aleatoriamente, mas por conveniência, com base nos sete perfis delineados pelo GoM.

Tais perfis forneceram um retrato das características mais recorrentes das mulheres em Belo Horizonte, a partir das variáveis selecionadas, permitindo que as entrevistadas escolhidas reproduzissem alguns aspectos da população feminina total do município entre 18 e 59 anos. Cabe ressaltar que nem todas as variáveis utilizadas no delineamento dos perfis foram utilizadas para o recrutamento, pois, quanto maior o número de características de uma entrevistada, maior a dificuldade em encontrá-la. Assim, optou-se por utilizar as variáveis demográficas e a posse de plano de saúde. No total, foram entrevistadas 61 mulheres de 18 a 59 anos, residentes em Belo Horizonte em 2005-2006, conforme o Quadro 1.

A técnica qualitativa utilizada foi a entrevista em profundidade, que "dá acesso às observações de outras pessoas a respeito de um fato. Através da entrevista, você pode

\footnotetext{
2 Para maiores detalhes sobre a amostragem, ver Miranda-Ribeiro e Caetano (2003).

3 Para maiores explicações sobre o Grade of Membership - GoM, ver Lacerda et al. (2005).

4 Para maiores detalhes sobre os perfis, ver Lacerda et al. (2006).
} 
aprender sobre lugares onde você nunca esteve e sobre experiências que você nunca viveu" (WEISS, 1994, p.1). As mulheres puderam, portanto, relatar suas próprias experiências, o que auxiliou na compreensão de aspectos que não haviam sido respondidos na etapa quantitativa. As entrevistas foram conduzidas por quatro pesquisadoras da equipe do projeto, ${ }^{5}$ a partir de um roteiro que continha as perguntas centrais a serem investigadas. $O$ roteiro foi concebido de forma a estimular a entrevistada a falar minuciosamente sobre aspectos gerais de sua saúde e de cuidados com a saúde, particularmente aqueles voltados à saúde reprodutiva. Ênfase especial foi dada às questões sobre realização de consultas ginecológicas, obtenção e uso de contraceptivos e conhecimento e realização do exame Papanicolau. Apesar do roteiro, a entrevistadora possuía liberdade para explorar, com maior profundidade, questões que não tivessem sido inicialmente contempladas, mas que fossem relativas, de alguma maneira, ao tema pesquisado. As entrevistas, com duração média de 45 minutos, foram gravadas, transcritas e analisadas.

\section{Conclusão}

Além da relevância do tema e das implicações dos resultados para as políticas na área de saúde municipal, o projeto Aspectos Quantitativos e Qualitativos Acerca do Acesso à Contracepção e ao Diagnóstico e Tratamento de Câncer de Colo Uterino: uma proposta de análise para o Município de Belo Horizonte, MG merece destaque por sua

QUADRO 1

Perfil das mulheres entrevistadas

Belo Horizonte - 2006

\begin{tabular}{|c|c|c|c|c|c|c|c|}
\hline Variável & Perfil 1 & Perfil 2 & Perfil 3 & Perfil 4 & Perfil 5 & Perfil 6 & Perfil 7 \\
\hline Escolaridade & 0-3 anos & 4-7 anos & 8-11 anos & $12 \mathrm{e}+$ anos & 8-11 anos & 4-11 anos & 8-11 anos \\
\hline Idade & 45-59 anos & $\begin{array}{l}25-34 \text { e } \\
40-44 \text { anos }\end{array}$ & $18-29$ anos & $\begin{array}{l}35-39 \\
45-49 \text { e } \\
55-59 \text { anos }\end{array}$ & $\begin{array}{l}18-29 \text { e } \\
45-49 \text { anos }\end{array}$ & 20-34 anos & 30-39 anos \\
\hline Raça/cor & $\begin{array}{l}5 \text { negras e } \\
2 \text { brancas }\end{array}$ & $\begin{array}{l}11 \text { negras e } \\
6 \text { brancas }\end{array}$ & Negras & $\begin{array}{l}12 \text { negras e } \\
3 \text { brancas }\end{array}$ & Negras & Negras & $\begin{array}{l}4 \text { negras e } \\
4 \text { brancas }\end{array}$ \\
\hline $\begin{array}{l}\text { Plano de } \\
\text { saúde }\end{array}$ & Não & Não & $\begin{array}{l}4 \text { não e } 4 \\
\text { sim }\end{array}$ & Sim & Não & Não & Sim \\
\hline Parturição & 3 e mais & 2 e mais & 0 ou 1 & 0 & $\begin{array}{l}0 \text { ou } 3 \mathrm{e} \\
\text { mais }\end{array}$ & 1 e mais & $\begin{array}{l}0,1,2,3 \mathrm{e} \\
\text { mais }\end{array}$ \\
\hline $\begin{array}{l}\text { Estado } \\
\text { conjugal }\end{array}$ & $\begin{array}{l}\text { Unidas, } \\
\text { separadas/ } \\
\text { divorciadas, } \\
\text { viúvas }\end{array}$ & $\begin{array}{l}\text { Casadas e } \\
\text { unidas }\end{array}$ & Solteiras & $\begin{array}{l}\text { Solteiras, } \\
\text { unidas, } \\
\text { separadas/ } \\
\text { divorciadas, } \\
\text { viúvas }\end{array}$ & $\begin{array}{l}\text { Solteiras, } \\
\text { unidas, } \\
\text { separadas/ } \\
\text { divorciadas, } \\
\text { viúvas }\end{array}$ & Casadas & $\begin{array}{l}\text { Casadas e } \\
\text { solteiras }\end{array}$ \\
\hline Religião & Católica & $\begin{array}{l}\text { Protestante/ } \\
\text { pentecostal }\end{array}$ & $\begin{array}{l}\text { Protestante/ } \\
\text { pentecostal } \\
\text { e espírita }\end{array}$ & $\begin{array}{l}\text { Espírita e } \\
\text { atéia }\end{array}$ & $\begin{array}{l}\text { Católica, } \\
\text { protestante/ } \\
\text { pentecostal }\end{array}$ & $\begin{array}{l}\text { Católica, } \\
\text { protestante/ } \\
\text { pentecostal }\end{array}$ & $\begin{array}{l}\text { Católica, } \\
\text { protestante/ } \\
\text { pentecostal }\end{array}$ \\
\hline $\begin{array}{l}\text { Total de } \\
\text { entrevistas }\end{array}$ & 7 & 17 & 8 & 15 & 2 & 4 & 8 \\
\hline
\end{tabular}

Fonte: SRSR, 2002.

\footnotetext{
${ }^{5}$ Andréa Branco Simão, Maria Eponina de Abreu e Torres, Marisa Alves Lacerda e Paula Miranda-Ribeiro (esta última com apenas uma entrevista). Como o tema em estudo era sensitivo e os sujeitos pesquisados eram do sexo feminino, todas as entrevistas foram conduzidas por pesquisadoras do sexo feminino.
} 
contribuição metodológica. A combinação de metodologia quantitativa e qualitativa se deu de forma inovadora. Pela primeira vez na Demografia, o método GoM - Grade of Membership foi utilizado a fim de gerar perfis

\section{Referências bibliográficas}

LACERDA, M. A.; MIRANDA-RIBEIRO, P.; CAETANO, A. J.; MACHADO, C. J. Mensuração e perfis de demanda insatisfeita por contracepção nos municípios de Belo Horizonte e Recife, 2002. Revista Brasileira de Estudos de População, v. 22, n. 1, p. 113-129, 2005.

LACERDA, M. A.; SIMÃO, A. B.; TORRES, M. E. A.; CAETANO, A. J.; MIRANDA-RIBEIRO, P.; PERPÉTUO, I. H. O. Perfis de acesso à contracepção e ao diagnóstico de câncer de que servissem de subsídio para o recrutamento de sujeitos em uma etapa qualitativa posterior. O GoM oferece a possibilidade de tornar o recrutamento de entrevistados um processo menos subjetivo.

colo uterino em Belo Horizonte, MG 2002. In: XV ENCONTRO NACIONAL DE ESTUDOS POPULACIONAIS, 2006, Caxambu. Anais... Campinas: Abep, 2006.

MIRANDA-RIBEIRO, P.; CAETANO, A. J. O Programa SRSR. Revista Brasileira de Estudos de População, v. 20, n. 2, p. 303305, 2003.

WEISS, R. S. Learning from strangers: the art and method of qualitative interview studies. New York: The Free Press, 1994.

Recebido para publicação em 22/08/2007. Aceito para publicação em 12/11/2007. 